\title{
Medication Review in Preventing Older Adults' Fall-Related Injury: a Systematic Review \& Meta-Analysis
}

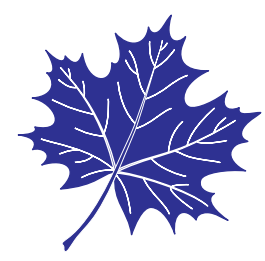

Yu Ming, $\mathrm{MD}, \mathrm{PhD}^{1}$, Aleksandra A. Zecevic, $\mathrm{PhD}^{2}$, Susan W. Hunter, $\mathrm{PhD}^{3}$, Wenxin Miao, $\mathrm{MSc}^{4}$, Rommel G. Tirona, $\mathrm{PhD}^{5}$

${ }^{1}$ Health and Rehabilitation Sciences, School of Health Studies, Western University, London; ${ }^{2}$ School of Health Studies, Western University, London; ${ }^{3}$ School of Physical Therapy, Western University, London; ${ }^{4}$ School of Information and Media Studies, Western University, London; ${ }^{5}$ School of Physiology and Pharmacology, Western University, London, ON

https://doi.org/10.5770/cgj.24.478

\section{ABSTRACT}

\section{Background}

Medication review is essential in managing adverse drug reactions and improving drug safety in older adults. This systematic review evaluated medication review's role as a single intervention or combined with other interventions in preventing fall-related injuries in older adults.

\section{Methods}

Electronic databases search was conducted in PubMed, EMBASE, Scopus, and CINAHL. Two reviewers screened titles and abstracts, reviewed full texts, and performed data extraction and risk of bias assessment. Meta-analyses were conducted on studies with similar participants, interventions, outcomes or settings.

\section{Results}

Fourteen randomized, controlled studies were included. The pooled results indicated that medication review as a standalone intervention was effective in preventing fall-related injuries in community-dwelling older adults (Risk Difference $\left.[\mathrm{RD}]=-0.06,95 \% \mathrm{CI}:[-0.11,-0.00], \mathrm{I}^{2}=61 \%, p=.04\right)$. Medication review also had a positive impact on decreasing the risk of fall-related fractures $(\mathrm{RD}=-0.02,95 \% \mathrm{CI}$ : [-0.04, $\left.-0.01], \mathrm{I}^{2}=0 \%, p=.01\right)$.

\section{Discussion}

This systematic review and meta-analysis has demonstrated that medication review is effective in preventing fall-related injuries in general, and fractures specifically, in communitydwelling older adults. Future investigations focusing on the process of performing medication review will further inform fall-related injury prevention for older adults.

Key words: medication review, falls, fall-related injuries, prevention, older adults

\section{INTRODUCTION}

Significance of injury in later life cannot be underestimated, especially in light of worldwide anticipated increase in number of older adults. Recent forecast indicates that from 2025 to 2050 the global population of older adults will double to 1.6 billion. ${ }^{(1)}$ About $30 \%$ of community-dwelling older adults fall each year and among these fallers, $30-50 \%$ of falls lead to minor injuries such as bruises or lacerations, while 5-10\% of falls result in serious injuries such as wrist or hip fractures, or traumatic brain injury (TBI). ${ }^{(2-7)}$ Fall-related injuries can have adverse consequences such as disability, reduced independence and mobility, a fear of falling, increased likelihood of admission to long-term care facilities, and higher risk of death. $(8,9)$ Fall-related injuries also pose substantial economic burden to an individual and the health-care system. ${ }^{(10,11)}$

Older adults are the largest consumers of prescription medications worldwide. ${ }^{(12,13)}$ The reduction of hepatic and renal functions, together with increased total body fat, predispose older adults to medication side effects, such as drug-drug and drug-disease interactions, that could lead to the increased risk of falls, injuries, hospital admissions, and diminished quality of life. ${ }^{(14-18)}$ Therefore, medication review is an essential process in preventing unintended fall-related consequences while managing chronic comorbidities in older adults. ${ }^{(19,20,21)}$ Medication review is defined as "a structured evaluation of patient's medicines with the aim of optimizing medicines use and improving health outcomes". ${ }^{(22)}$ A number of randomized trials, systematic reviews, and meta-analyses have examined the effectiveness of medication review in reducing the mortality, ${ }^{(19,23,24-28)}$ hospital admissions and health-care use, ${ }^{(19,23,24-27,29-31)}$ preventing falls, ${ }^{(3,28,31)}$ and improving quality of life $(19,27,31)$ in older adults. However, no study reported positive impact of medication review on enhancing quality of life or reducing mortality of patients. Conflicting results were reported on hospital admissions 
reduction and ADR (Adverse Drug Responses) alleviation. In this review "fall-related injury" is a specific outcome, with focus on "injury" not the fall. To date, no systematic review focused specifically on examining the effectiveness of medication review in fall-related injury prevention.

This aim of this study was to summarize the evidence on the effectiveness of medication review, as either a single intervention or a component included in multifactorial interventions, on preventing fall-related injuries in older adults.

\section{METHODS}

This systematic review and meta-analysis were registered with PROSPERO on 28th April, 2020 (Registration number: CRD42020161567) and followed Preferred Reporting Items for Systematic Reviews and Meta-Analyses (PRISMA) recommendation $^{(32)}$ (see Appendix A). Electronic database searches were conducted in PubMed, CINAHL, EMBASE, and Scopus using a combination of keywords, controlled vocabulary terms, and free-text terms with various substitution forms for the three search themes- "medication review", "fall-related injuries" and "older adults". For "fall-related injuries", different types of injuries were included, such as sprains and strains, dislocations, perforations, lacerations, penetrations, and fractures. Injuries of different body parts included head, teeth, neck, shoulder, arm, hand, abdominal, hip, leg, foot, tendon, soft tissue, spinal cord, and vascular system injuries. Hospitalizations and episodes of seeking medical treatment in clinical facilities were also included as possible indications of fall-related injuries. Adults 65 years of age or older were eligible participants, defined by the term "older adults" and its synonyms specifically identified in titles and abstracts. An example of a detailed search strategy for PubMed is provided in Appendix B.

Only patient-randomized controlled trials and clusterrandomized controlled trials of older adults living in the community, long-term care facilities, and hospitals were included in this review. Studies were also taken into consideration if the mean age was greater than 65 years. Medication review had to be a single intervention or one component of a multi-factorial intervention for prevention of fall-related injuries in older adults. The comparison was defined as usual care. Injuries, hospitalizations, and episodes of seeking medical treatment in clinical facilities due to falls were defined as outcomes.

After removal of duplicates, two reviewers (YM and WM) independently screened titles and abstracts using the Covidence online software (https://www.covidence.org) to determine if the studies met the inclusion criteria. Studies without full text and those not published in the English language were excluded. Two reviewers (YM and WM) extracted details of included studies independently, using a specially designed data extraction form. The information extracted from the included studies included the authors, year of publication, study design, participants, settings, definition of fall and fall-related injuries, interventions, definition of medication reviews, comparisons, outcome measures, length of follow-up, sample size calculation, statistical analysis methods, and main results. Four authors were contacted by email to obtain missing information or clarifications. ${ }^{(33-36)}$ Salminen et al. ${ }^{(35)}$ provided information on the mean age of the participants, and Sjöberg and Wallerstedt ${ }^{(36)}$ provided information on the calculation of the sample size. No response was received from the other two authors.

All selected studies were assessed by two reviewers (YM and WM) for risk of bias using the Cochrane Collaboration's tool for assessing risk of bias in randomized trials. ${ }^{(37)}$ The two reviewers also applied four additional criteria designed by Cochrane Effective Practice and Organization of Care Group. ${ }^{(38)}$ For each domain, the reviewers independently made judgements on whether the studies were at low, high or unclear risk of bias, and recorded them in individual tables.

Meta-analysis was performed using Review Manager 5.3 (RevMan 5.3; Cochrane Collaboration/Cochrane Training, London UK). The Inverse Variance method and RandomEffect Model were used to calculate Risk Differences (RDs) between the intervention and control group. Random effects approach was chosen because it could statistically adjust to some extent for the heterogeneity among studies. ${ }^{(39)}$ Sources of heterogeneity were explored by a priori subgroup analyses. Subgroup analysis was conducted according to (1) different injury types, (e.g., operationally defined as fall-related injuries, fractures or hospital admissions due to falls), (2) different interventions (e.g., medication review as a single intervention or included in a multifactorial fall prevention program), and (3) participants, (e.g., low risk vs. high risk of falling). Sensitivity analysis was performed for pooled results based on the risk of bias. A funnel plot was created for the estimated RDs of 11 community-based studies.

\section{RESULTS}

\section{Characteristics of Included Studies}

The search of EMBASE, PubMed, CINAHL, and Scopus produced 479, 437, 146, and 829 citations, respectively. Among 1,891 citations, 134 were duplicates and 1,740 articles were excluded during screening of the titles and abstracts, leaving 17 studies for the full-text screening. Three studies were excluded because they lacked detailed descriptions of the medication review. Finally, 14 studies were included in this systematic review (Figure. 1).

The characteristics of included studies are summarized in Table 1. Seven studies were patient-randomized controlled trials and seven were cluster-randomized controlled trials. Four studies were conducted in the UK, ${ }^{(40-43)}$ three in Sweden, ${ }^{(33,36,44)}$ two in Finland, ${ }^{(35,45)}$ two in Australia, ${ }^{(34,46)}$ and one each in US, ${ }^{(47)}$ the Netherlands, ${ }^{(48)}$ and Singapore. ${ }^{(49)}$ Eleven studies ${ }^{(34-36,40,41,43,45-49)}$ involved community-dwelling older adults, one study hospital patients, ${ }^{(42)}$ and two studies long-term care homes residents. ${ }^{(33,44)}$ Sample size ranged from 186 to 3,384 participants. Eight studies used fall-related injuries as outcomes, ${ }^{(34,40,42,44-47,49)}$ two studies used fractures, ${ }^{(33,36)}$ two studies used fall-related hospitalization, ${ }^{(41,43)}$ and two 


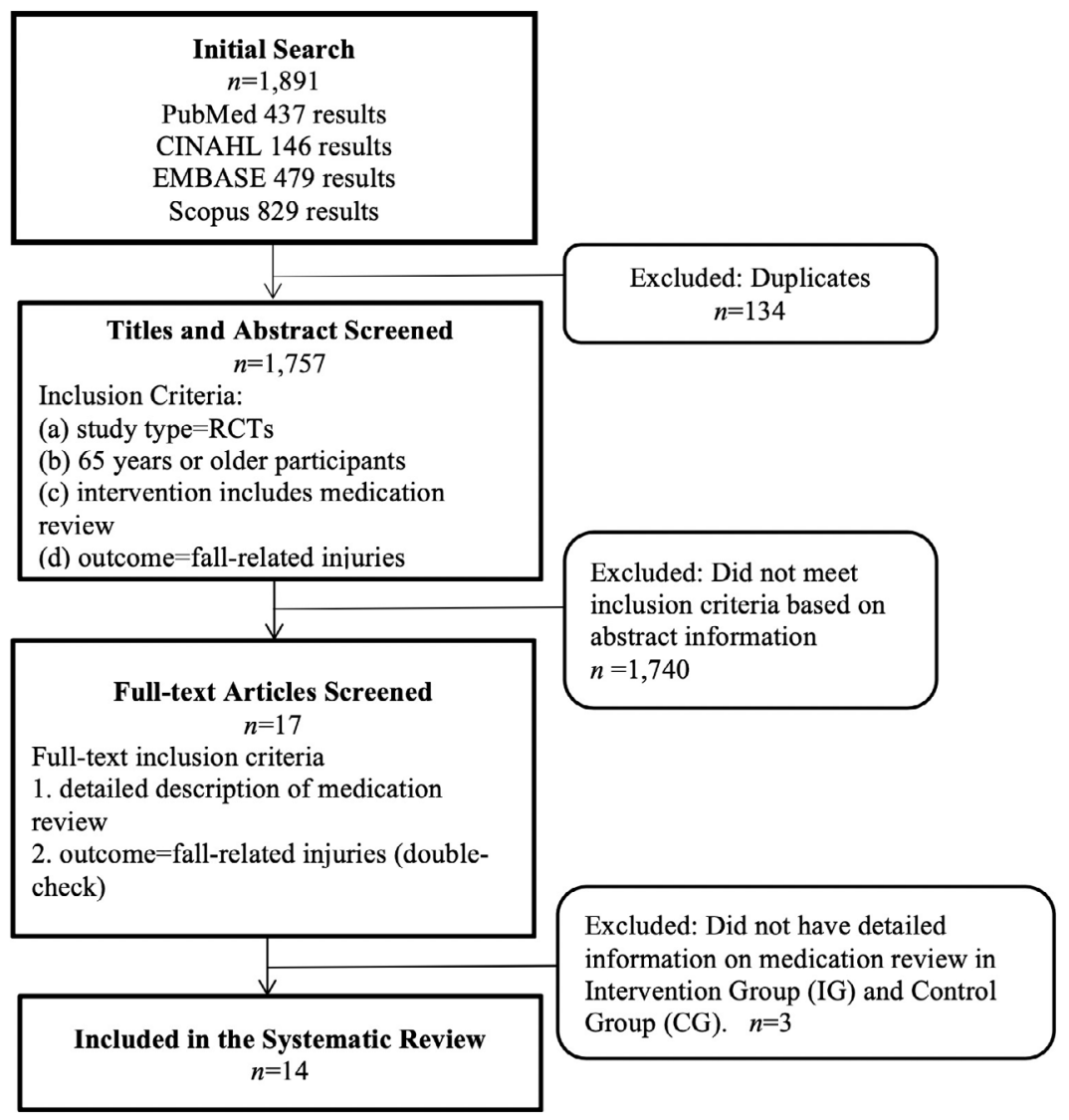

FIGURE 1. Fourteen studies were included in this systematic review

used falls requiring medical treatment, general practitionerconsultations or emergency department (ED) visits. ${ }^{(35,48)}$

Detailed information on medication review performed in each study is summarized in Table 2. Four studies ${ }^{(34,36,47,48)}$ used medication review as a single intervention, while ten studies assessed the effect of medication review as a part of multifactorial interventions to prevent fall-related injuries. $(33,35,40-46,49)$ In six studies, a physician reviewed the prescription medications used by the patients and made the final decision on whether to change the regimen. ${ }^{(33,34,41,42,44,45)}$ In three studies, geriatricians reviewed the medication regimen and forwarded their suggestions to participants' family physicians for decision-making. ${ }^{35,36,40)}$ There were two studies in which pharmacists, geriatricians, and physicians collaborated on medication reviews. ${ }^{(46,48)}$ In two studies, nurses or physiotherapists reviewed medication use according to strict pre-planned strategies, ${ }^{(43,49)}$ while Blalock et al. ${ }^{(47)}$ used pharmacists to review the patients' medications. In all studies, reduction or cancellation in the medication regimens were decided by physicians. Researchers in 12 studies performed only one systematic medication review. Sjöberg and Wallerstedt $^{(36)}$ performed three medication reviews over a 12-month period, and Palvanen et al. ${ }^{(45)}$ conducted a second medication review for patients at sixth months during a 12-months followup period. Twelve studies had a 12-month follow-up period, while Salmimen et al. ${ }^{(35)}$ followed patients for 36 months, and Matchar et al. ${ }^{(49)}$ followed patients for nine months. Six studies focused on participants with high risk of falling or fall-related injuries. ${ }^{(35,40,43,45,47,48)}$ The risk in these studies was determined by previous fall history, taking more than four medications or taking more than one CNS-active drug.

\section{Risk of Bias in Included Studies}

Figure 2 and Figure 3 summarized the risk of bias in the 14 included studies. On average, studies had five (range 2-6) out of 11 domains in the low risk of bias. Most studies had low risk of bias on randomization and allocation concealment. Due to the nature of medication review, it was not practical to blind participants or personnel in such studies. The two reviewers judged all the studies to have high risk of performance bias. The authors of seven studies ${ }^{(40-42,45-47,49)}$ were able to blind the outcome assessors, resulting in low detection bias. Six studies were found to have high risk of bias on the reliability of the outcome measurement because the fall-related injuries were self-reported by patients. ${ }^{(34,40,41,43,47,49)}$ Remaining studies had low bias in reliability of outcome measurement, as they confirmed injuries by physicians, ${ }^{(33,44)}$ through medical records, ${ }^{(36,45)}$ hospital's Health and Safety Department, ${ }^{(42)}$ health centre, hospital registers ${ }^{(35)}$ or health service use. ${ }^{(46,48)}$ Only two studies ${ }^{(47,48)}$ had published research protocols and reported all the outcomes stated in the method section, so they were judged to have low risk of reporting bias. 


\section{Intervention Effect}

Four studies reported positive results, ${ }^{(33,34,45,49)}$ while the remaining 10 studies did not find that medication review as a single intervention or a part of multifactorial interventions was effective in preventing fall-related injuries in older adults.

0Jensen et al. ${ }^{(33)}$ detected 145 injuries in 691 falls among 362 older adults who lived in nine residential care facilities in Sweden. The adjusted odds ratio (aOR) for having a femoral fracture was 0.23 (95\% CI: $0.06-0.94)$. Pit et al. ${ }^{(34)}$ found that, after adjustment for clustering effect, there was significant reduction in fall-related injuries $(\mathrm{aOR}=0.56,95 \% \mathrm{CI}$ : 0.32 $0.96)$ and other consequences that needed medical attention $(\mathrm{aOR}=0.46,95 \% \mathrm{CI}: 0.30-0.70)$ in the intervention group by the end of 12-month follow-up. Palvanen et al. ${ }^{(45)}$ reported that fall-induced injury risk ratio (RR) was significantly deceased (0.74 with $95 \%$ CI: $0.61-0.89, p=.002$ ) in the intervention group (i.e., multifactorial fall prevention program), compared to older adults with usual care. The aOR for fall-related medical attention was 0.46 (95\% CI: 0.30-0.70) in the intervention group. Matchar et al. ${ }^{(49)}$ showed that the relative risk of injurious falls in the intervention group was 0.56 (95\% CI: $0.32-0.98, p=.041)$. They also completed a sub-group analysis on patients with $0-1$ critical comorbidity vs. patients with two or more comorbidities and concluded that the intervention was more effective in patients without major comorbidities.

\section{Meta-Analyses}

Pooled results from 11 studies conducted with communitydwelling participants produced 714 fall-related injuries in the intervention group and 913 in the control group. ${ }^{(34-36,40-42,45-49)}$ The meta-analysis showed that the risk difference of -0.07 (95\% CI: -0.11 to $-0.02, p=.007$, heterogeneity: $\chi^{2}=47.30$, $\left.\mathrm{df}=10(p<.00001) ; \mathrm{I}^{2}=79 \%\right)$ was significantly different in favour of the intervention group (see Figure 4).

Results of five studies in which fall-related fractures were outcomes ${ }^{(33,36,41,43,45)}$ were pooled together, and the heterogeneity was low $\chi^{2}=2.30, \mathrm{df}=4, p=.68 ; \mathrm{I}^{2}=0 \%$ ). The pooled results favored the intervention group slightly with the $\mathrm{RD}=-0.02$ ( $95 \% \mathrm{CI}$ : -0.04 to $-0.01, p=.01$; Figure 5 ).

Results of four studies using medication review as a single intervention $(34,36,47,48)$ were pooled together and the heterogeneity was low $\left(\chi^{2}=5.13, \mathrm{df}=3, p=.16, \mathrm{I}^{2}=41 \%\right)$. They suggested that, compared with usual care, medication review alone can lower the risk of fall-related injuries in community-dwelling older adults $(\mathrm{RD}=-0.07,95 \% \mathrm{CI}$ : -0.11 to $-0.02, p=.008$; Figure 6 ).

The pooled results of two studies which used hospital admission due to falls as an outcome ${ }^{(41,43)}$ indicated low heterogeneity (Figure 7), but were inconclusive to show if the intervention group had lower risk of fall-related admissions, compared to the control group ( $\mathrm{RD}=-0.03,95 \% \mathrm{CI}$ : -0.09 to $0.02, p=.23$ ).

Sensitivity analysis was performed for three studies $(45,46,49)$ with low risks of bias which focused on fall-related injuries in community-dwelling adults. When pooled, there was high heterogeneity (Figure 8), but the intervention group had a significantly lowered risk of fall-related injuries, compared with the control group, with $\mathrm{RD}=-0.16(95 \% \mathrm{CI}:-0.23$ to $-0.08, p<.0001)$.

TABLE 1.

Summary of the characteristics of included studies

\begin{tabular}{lllcccl}
\hline \multicolumn{1}{c}{ Author (Year) } & \multicolumn{1}{c}{ Country } & \multicolumn{1}{c}{ Settings } & $\begin{array}{c}\text { No. of Pts } \\
(I G / C G)\end{array}$ & $\begin{array}{c}\text { Calculated SS } \\
(I G / C G)\end{array}$ & $\begin{array}{c}\text { Mean age } \pm \text { SD } \\
(I G / C G)\end{array}$ & Fall-related Outcome \\
\hline Jensen $^{(33)}(2002)$ & Sweden & LTC & $181 / 181$ & N/A & $82.2 \pm 7.5 / 83.9 \pm 5.8$ & Femoral fracture \\
Jensen $^{(44)}(2003)$ & Sweden & LTC & $181 / 181$ & N/A & $82.2 \pm 7.5 / 83.9 \pm 5.8$ & Fall-related injuries \\
Healey $^{(42)}(2004)$ & UK & Hospital & $1,525 / 1,859$ & $1,500 / 1,500$ & $81.4 / 81.2$ & Fall Injury \\
Davison $^{(41)}(2005)$ & UK & Community & $159 / 154$ & $176 / 176$ & $77.0 \pm 7.0 / 77.0 \pm 7.0$ & Hospital admission \\
Pit $^{(34)}(2007)$ & Australia & Community & $452 / 397$ & $398 / 398$ & N/A & Fall injury \\
Salminen $^{(35)}(2009)$ & Finland & Community & $293 / 298$ & $229 / 229$ & $73.4 \pm 6.0 / 73.5 \pm 6.3$ & Falls requiring treatment \\
Spice $^{(43)}(2009)$ & UK & Community & $141 / 162$ & $172 / 172$ & $81.0 \pm 6.6 / 83.0 \pm 6.6$ & Hospital admission \\
Conroy $^{(40)}(2010)$ & UK & Community & $183 / 181$ & $200 / 200$ & $78.4 \pm 5.6 / 79.1 \pm 5.7$ & Injurious falls \\
Blalock $^{(47)}(2010)$ & USA & Community & $93 / 93$ & $95 / 95$ & $75.5 \pm 7.0 / 74.1 \pm 6.8$ & Injurious falls \\
Sjöberg( $^{(36)}(2013)$ & Sweden & Community & $100 / 100$ & $100 / 100$ & $84.0 \pm 6.9 / 85.0 \pm 7.3$ & Fractures \\
Palvanen $^{(45)}(2014)$ & Finland & Community & $661 / 653$ & $1,600 / 1,600$ & $77.5 \pm 5.6 / 77.7 \pm 6.7$ & Fall-induced injuries \\
Boyé(48) $(2016)^{(2016)}$ & Netherland & Community & $319 / 293$ & $310 / 310$ & $76.5 \pm 7.2 / 76.4 \pm 7.4$ & Falls requiring GP or ED visits \\
Mikolaizak $^{(46)}(2017)$ & Australia & Community & $111 / 110$ & $117 / 117$ & $83.9 \pm 6.9 / 82.8 \pm 7.5$ & Injurious falls \\
Matchar $^{(49)}(2017)$ & Singapore & Community & $177 / 177$ & $165 / 165$ & $78.2 \pm 6.9 / 77.4 \pm 7.2$ & Injurious Falls \\
\hline
\end{tabular}

No. = number; Pts = participants; $\mathrm{SD}=$ standard deviation; $\mathrm{SS}=$ sample size; $\mathrm{IG}=$ intervention group; $\mathrm{CG}=$ control group; $/ \mathrm{A}=$ not available; $\mathrm{GP}=$ general practitioner; ED = Emergency Department. 


\section{MING: MEDICATION REVIEW AND FALL-RELATED INJURY}

The funnel plot (Figure 9) showed asymmetry, indicating the existence of either publication bias or heterogeneity. A thorough examination on the literatures did not disclose other unpublished peer-reviewed studies, so the publication bias was regarded as of low risk. The heterogeneity could be explained by variation in population size, the different ways of performing medication reviews and different outcomes (such as fall-related fractures, fall-related hospitalizations, and fall-related injuries that required medical consultations).

\section{DISCUSSION}

In this systematic review and meta-analysis, medication review, either as a single intervention or a part of multi-factorial

TABLE 2.

Summary of medication review characteristics of included studies

\begin{tabular}{|c|c|c|c|c|c|c|c|}
\hline Author (Year) & Design & $\begin{array}{c}\text { HCP } \\
\text { Involvement }\end{array}$ & Patient-I & $\begin{array}{l}\text { No. } \\
\text { of } R\end{array}$ & $\begin{array}{l}\text { HCP } \\
\text { Training }\end{array}$ & $\begin{array}{l}\text { Follow-up } \\
\text { (months) }\end{array}$ & Study Inclusion Criteria \\
\hline $\begin{array}{l}\text { Jensen }^{(33)} \\
(2002)\end{array}$ & M & $\begin{array}{l}\text { R: physician } \\
\text { D: physician }\end{array}$ & No & 1 & Yes & 12 & 1. $\geq 65$ years; 2 . Living in nursing homes \\
\hline $\begin{array}{l}\text { Jensen }^{(44)} \\
(2003)\end{array}$ & M & $\begin{array}{l}\text { R: physician } \\
\text { D: physician }\end{array}$ & No & 1 & Yes & 12 & 1. $\geq 65$ years; 2 . Living in nursing homes \\
\hline $\begin{array}{l}\text { Healey }^{(42)} \\
(2004)\end{array}$ & M & $\begin{array}{l}\text { R: physician } \\
\text { D: physician }\end{array}$ & No & 1 & No & 12 & $\begin{array}{l}1 . \geq 65 \text { years; } 2 \text {. Received care in hospital wards } \\
\text { and community units }\end{array}$ \\
\hline $\begin{array}{l}\text { Davison }^{(41)} \\
(2005)\end{array}$ & M & $\begin{array}{l}\text { D: physician } \\
\text { R: physician }\end{array}$ & No & 1 & No & 12 & $\begin{array}{l}1 . \geq 65 \text { years; } 2 \text {. Presenting to A\&E with a fall or } \\
\text { fall-related injury; } 3 \text {. Community-dwelling }\end{array}$ \\
\hline $\mathrm{Pit}^{(34)}(2007)$ & $\mathrm{S}$ & $\begin{array}{l}\text { D: physician } \\
\text { R: physician }\end{array}$ & No & 1 & Yes & 12 & 1. $\geq 65$ years; 2 . Community-dwelling \\
\hline $\begin{array}{l}\text { Salminen }^{(35)} \\
(2009)\end{array}$ & M & $\begin{array}{l}\mathrm{R} \text { : geriatrician } \\
\mathrm{D} \text { : physician }\end{array}$ & Yes & 1 & No & 36 & $\begin{array}{l}\text { 1. } \geq 65 \text { years; } 2 \text {. At least one fall during the } \\
\text { previous year; } 3 \text {. MMSE } \geq 17 ; 4 \text {. Able to walk for } \\
10 \text { min; } 5 \text {. Living at home }\end{array}$ \\
\hline $\begin{array}{l}\text { Spice }^{(43)} \\
(2009)\end{array}$ & M & $\begin{array}{l}\text { R: nurse } \\
\text { D: physician }\end{array}$ & No & 1 & No & 12 & $\begin{array}{l}\text { 1. } \geq 65 \text { years; } 2 . \geq 2 \text { falls in the preceding year; } \\
\text { 3. Living in community }\end{array}$ \\
\hline $\begin{array}{l}\text { Conroy }{ }^{(40)} \\
(2010)\end{array}$ & M & $\begin{array}{l}\mathrm{R} \text { : geriatrician } \\
\mathrm{D} \text { : physician }\end{array}$ & No & 1 & No & 12 & $\begin{array}{l}\text { 1. } \geq 70 \text { years; } 2 . \geq 1 \text { fall in the previous year or } \geq 2 \\
\text { of other falls risk factors; } 3 \text {. Living in community }\end{array}$ \\
\hline $\begin{array}{l}\text { Blalock }^{(47)} \\
(2010)\end{array}$ & $\mathrm{S}$ & $\begin{array}{l}\mathrm{R}: \text { pharmacist } \\
\mathrm{D} \text { : physician }\end{array}$ & Yes & 1 & No & 12 & $\begin{array}{l}\text { 1. } \geq 65 \text { years; } 2 . \geq 1 \text { falls preceding } 1 . \geq 65 \text { years; } \\
\text { 2. } \geq 1 \text { falls preceding randomization; } 3 \text {. Taking } \\
\geq 4 \text { prescription or } \geq 1 \text { CNS-active medications; } \\
\text { 4. Living in community }\end{array}$ \\
\hline $\begin{array}{l}\text { Sjöberg(36) } \\
(2013)\end{array}$ & $\mathrm{S}$ & $\begin{array}{l}\text { R: geriatrician } \\
\text { D: physician }\end{array}$ & No & 3 & Yes & 12 & $\begin{array}{l}1 . \geq 65 \text { years; } 2 \text {. Undergone surgery for a hip } \\
\text { fracture }\end{array}$ \\
\hline $\begin{array}{l}\text { Palvanen }{ }^{(45)} \\
(2014)\end{array}$ & M & $\begin{array}{l}\text { R: physician } \\
\text { D: physician }\end{array}$ & No & 2 & Yes & 12 & $\begin{array}{l}\text { 1. } \geq 70 \text { years; } 2 \text {. Increased risk for falling or } \\
\text { fall-induced injuries; } 3 \text {. Living in community }\end{array}$ \\
\hline $\begin{array}{l}\text { Boyé(48) } \\
(2016)\end{array}$ & $\mathrm{S}$ & $\begin{array}{l}\text { R: geriatrician- } \\
\text { pharmacist- } \\
\text { physician } \\
\text { D: physician }\end{array}$ & No & 1 & No & 12 & $\begin{array}{l}\text { 1. } \geq 65 \text { years; } 2 \text {. Attended the ED due to a } \\
\text { fall; } 3 \text {. } \geq 1 \text { FRIDs for } \geq 2 \text { weeks prior to a fall; } \\
\text { 4. MMSE } \geq 21 ; 5 \text {. Able to walk independently; } \\
\text { 6. Living in community }\end{array}$ \\
\hline $\begin{array}{l}\text { Mikolaizak }^{(46)} \\
(2017)\end{array}$ & M & $\begin{array}{l}\text { R: pharmacist- } \\
\text { geriatrician } \\
\text { D: pharmacist- } \\
\text { physician }\end{array}$ & No & 1 & No & 12 & $\begin{array}{l}\text { 1. } \geq 65 \text { years; } 2 \text {. Received a fall-related emergency } \\
\text { response from paramedics; } 3 \text {. Living in } \\
\text { community }\end{array}$ \\
\hline $\begin{array}{l}\text { Matchar } \\
(2017)\end{array}$ & M & $\begin{array}{l}\text { R: PT } \\
\text { D: physician }\end{array}$ & No & 1 & No & 9 & $\begin{array}{l}\text { 1. } \geq 65 \text { years; } 2 \text {. Seen in the ED for a fall or } \\
\text { fall-related injury; } 3 \text {. Able to perform Three- } \\
\text { Step Command Test; } 4 \text {. Discharged or admitted } \\
\text { to hospital but able to recover within } 1 \text { month; } \\
\text { 5. Community-dwelling }\end{array}$ \\
\hline
\end{tabular}

$\mathrm{HCP}=$ Health Care Professional; Patient- $\mathrm{I}=$ patient involvement $\mathrm{R}=$ medication review $\mathrm{S}=$ medication review as single intervention; $\mathrm{M}=$ medication review was one of the components in a multi-factorial intervention; $\mathrm{D}=$ decision on medication change; $\mathrm{PT}=$ physiotherapist. 


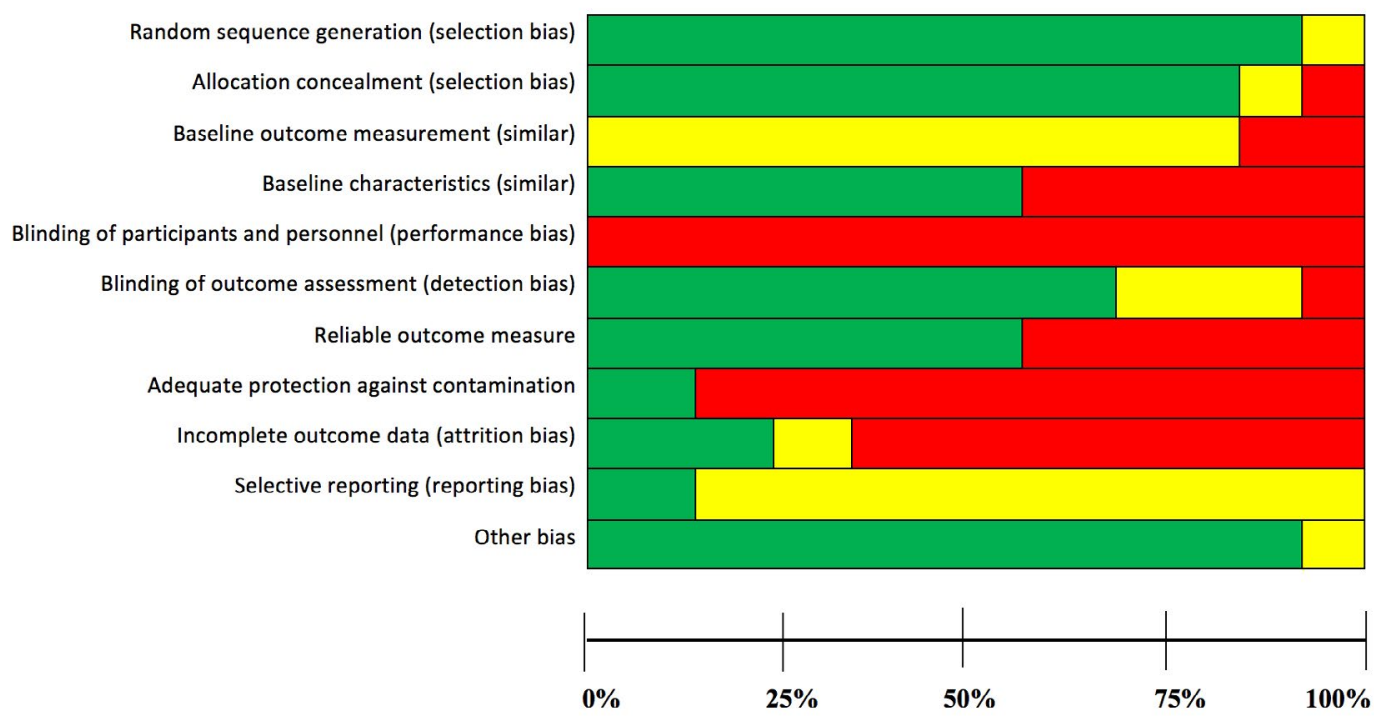

FIGURE 2. Risk of bias summary graph: each risk of bias item presented as percentage across all included studies

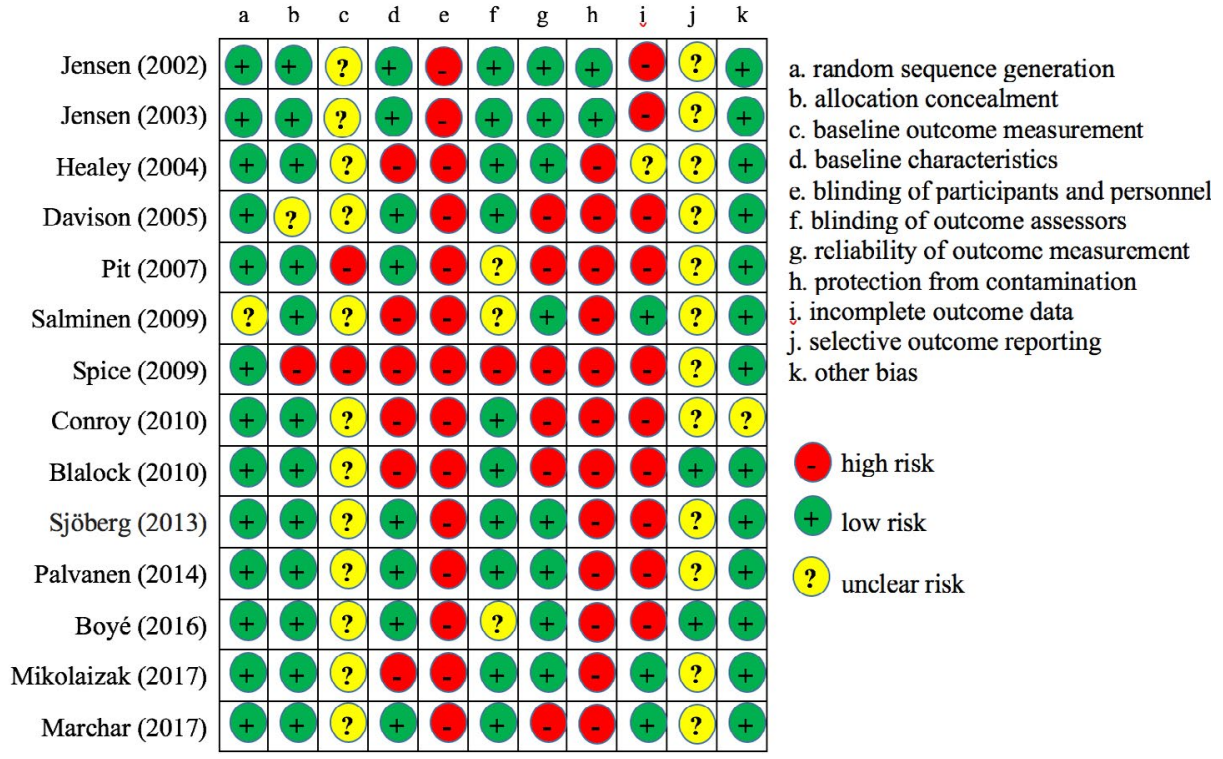

FIGURE 3. Risk of bias summary: each risk of bias item for each included study

fall prevention program, was found to be effective in preventing fall-related injuries and fall-related fractures in community-dwelling older adults. Moreover, a beneficial effect of medication review as the sole intervention was found in reducing fall-related risk of injuries. However, the review was not conclusive on whether medication review was effective in reducing fall-related hospital admissions in older-adults. To the authors' knowledge, this is the first systematic review exploring the effectiveness of medication review in preventing fall-related injuries in older adults. The results suggest that improvement in prevention of fall-related injuries can be achieved by the delivery of medication reviews in communitydwelling older adults.

In 2011, the American Geriatrics Society and British Geriatrics Society Clinical Practice Guideline for Prevention of Falls in Older Persons identified strong evidence to support withdrawal of psychotropic medication for older adults. ${ }^{21)}$ The Registered Nurses' Association of Ontario (RNAO) falls prevention guidelines also recommended conducting medication review or referring to appropriate health-care provider to reduce, gradually withdraw or discontinue medications that are associated with falling, ${ }^{(50)}$ but their evidence was obtained from expert opinion or committee reports. The findings presented here provide further evidence on the positive role of medication review in preventing fall-related injuries in older adults, thus supporting prominent practice guidelines recommendations.

The results of the meta-analysis indicated high heterogeneity among the included studies. Several factors can explain this variation. First, there is a lack of standardized process on how to perform a medication review. Various tools are available 


\section{MING: MEDICATION REVIEW AND FALL-RELATED INJURY}

to health-care professionals to optimize patients' medication, prevent inappropriate prescribing, and minimize adverse drug reactions and polypharmacy. Examples are the Screening Tool of Older Person's Prescriptions (STOPP) and Screening Tool to Alert doctors to Right Treatment (START), ${ }^{(51)}$ Beers criteria, ${ }^{(52)}$ Medication Appropriate Index, ${ }^{(53)}$ and Drug Burden Index. ${ }^{(54)}$ However, none of these tools is all-inclusive to be regarded as a gold standard. In such context, the performance of medication review is greatly based on the personal assessment and judgement built on pharmacists' or physicians' knowledge of medications, comprehensive understanding of patients' clinical information, and efficient communication and cooperation between health-care providers. ${ }^{(55)}$ Secondly, researchers in different studies designed their patient selection criteria to optimize detection of intervention effects. Seven studies chose older adults with high risk of falling, with the assumption that this group could benefit the most from medication review.

The strengths of this review include the methodological rigor, detailed, and comprehensive search strategies, strict inclusion and exclusion criteria, a high inter-rater agreement between the two reviewers when screening the titles and abstracts, a strict requirement for a detailed description of the medication review process to facilitate comparison between trials, and acceptably low risk of bias of included studies, thus producing convincible results.

Several limitations are associated with this systematic review and meta-analysis. Inclusion of only studies published in English language resulted in exclusion of 44 non-English

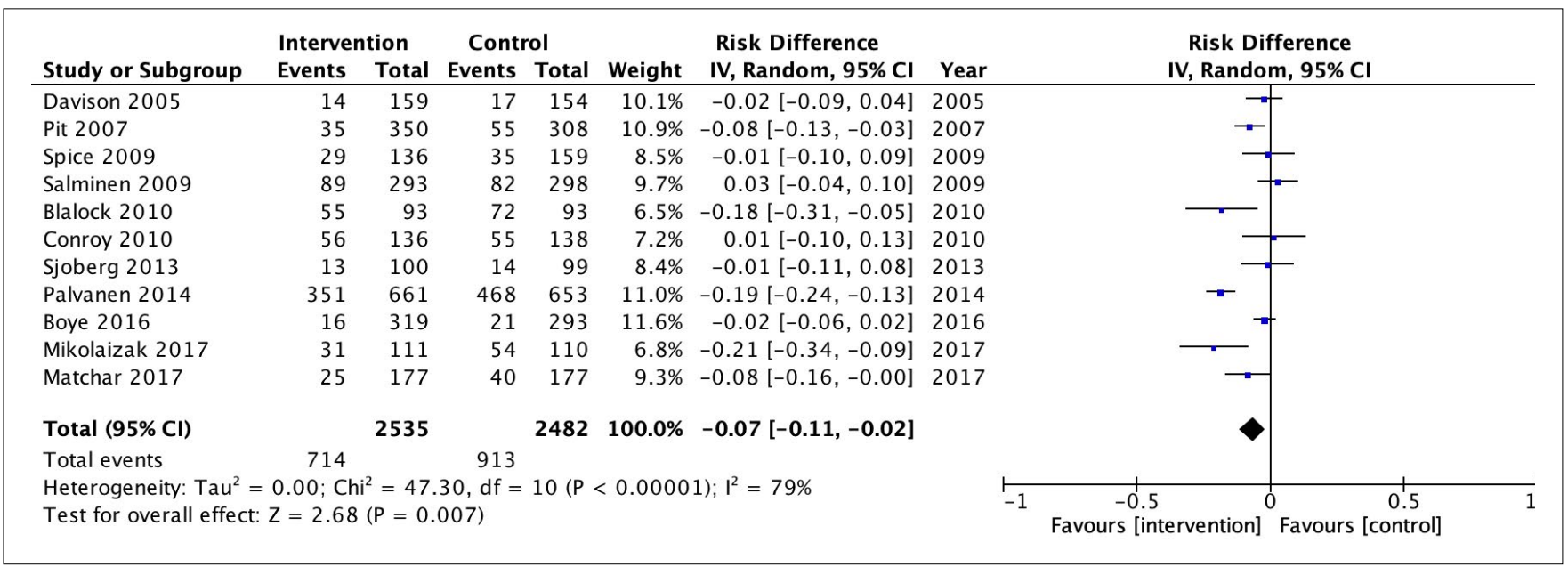

FIGURE 4. Risk of difference in community-dwelling participants

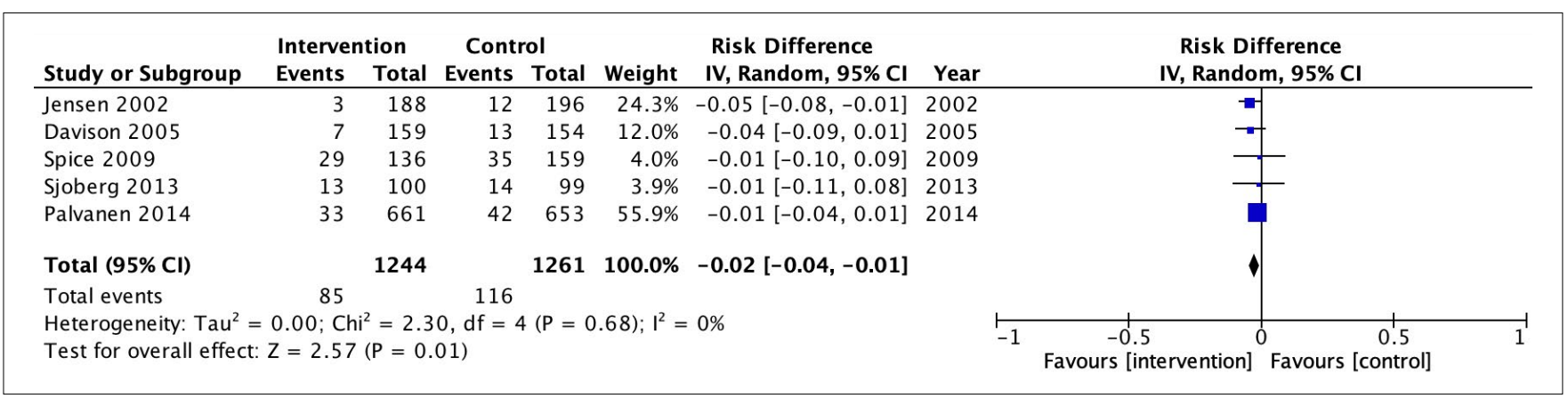

FIGURE 5. Results of five studies of fall-related fractures

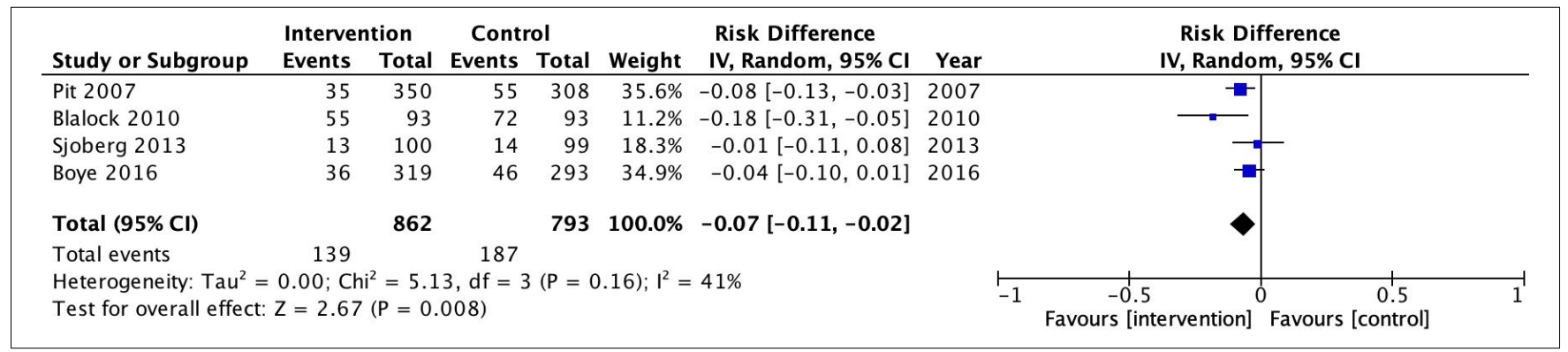

FIGURE 6. Results of four studies using medication review as a single intervention 
MING: MEDICATION REVIEW AND FALL-RELATED INJURY

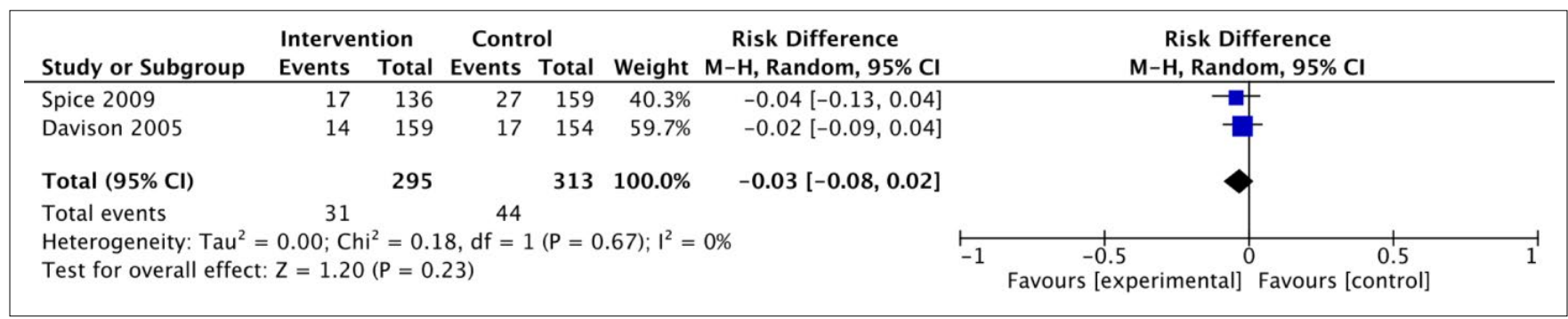

FIGURE 7. Pooled results from two studies investigating effects of medication review on fall-related hospital admissions in community-dwelling older adults

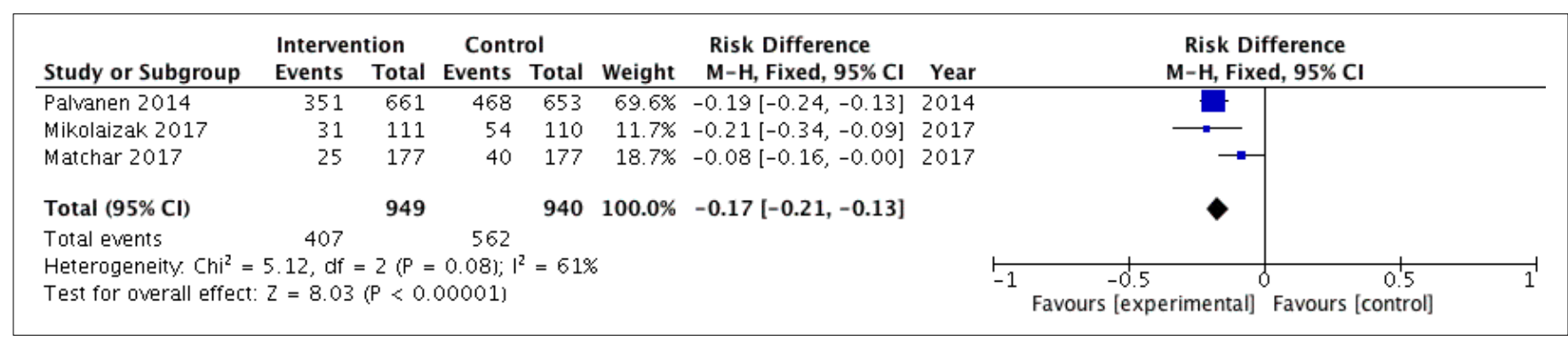

FIGURE 8. Pooled results from three studies with low risk of bias investigating effects of medications review on fall-related injuries in community-dwelling older adults

studies during the titles and abstracts screening. A close examination of translated abstracts revealed that these studies would not meet other inclusion criteria; hence, it is unlikely that their exclusion would have impacted the study findings. Due to the nature of the studies, where the blinding of participants and intervention providers was impractical, the risk of performance bias was high. This has the potential to undermine the results of this review, but statistically significant associations noted in the meta-analyses point to at least conservative estimates of the intervention effect. Next, although only four studies used medication review as the single intervention for fall-related injury prevention, they all demonstrated a positive effect. For the remaining 10 studies, where medication review was a part of multifactorial fall prevention programs, even when a positive effect was detected, it could not be ascribed solely to the medication review. Finally, contamination of the control group could not be avoided, because medication reviews have become a widespread part of the usual geriatric care.

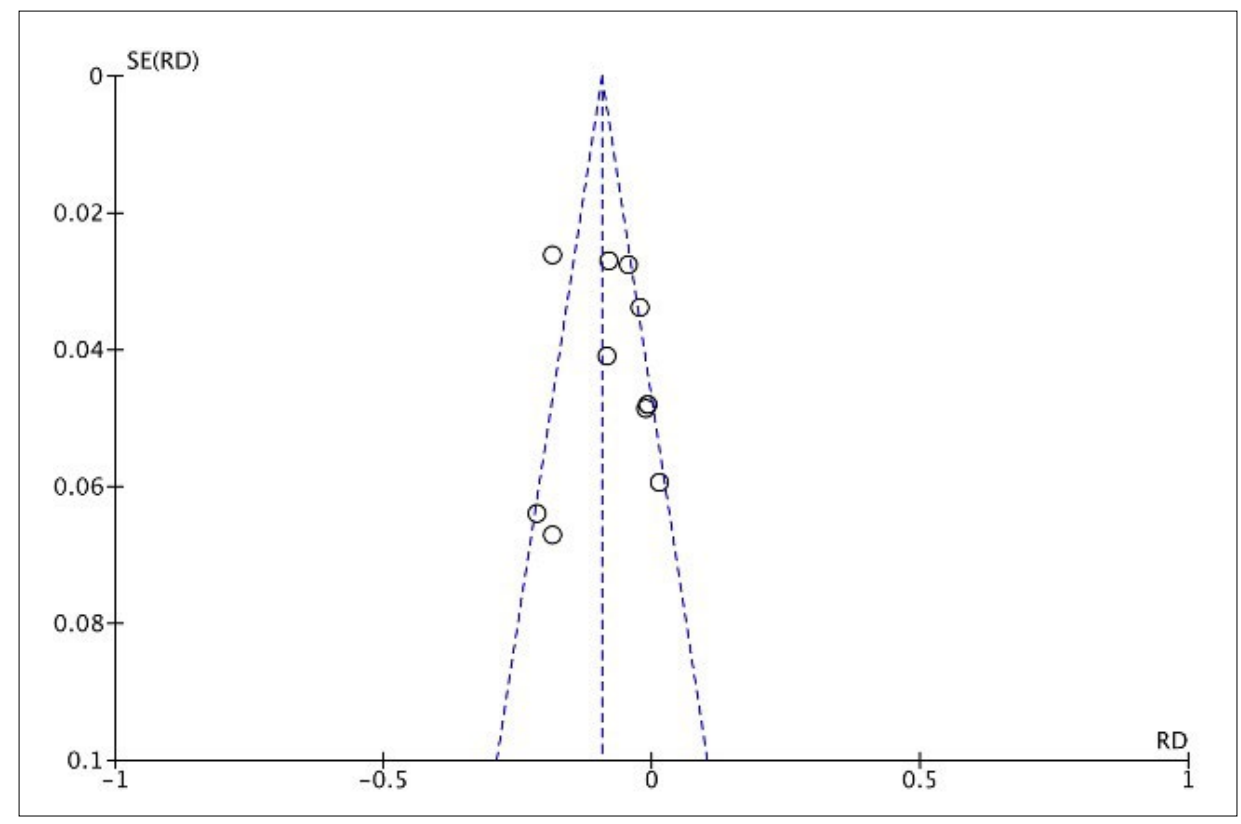

FIGURE 9. Funnel plot of 11 studies including community-dwelling participants 


\section{CONCLUSION}

This systematic review and meta-analysis summarized evidence from 14 randomized controlled studies to identify the effectiveness of medication review, either as a single intervention or combined in multi-factorial fall prevention programs, on preventing fall-related injuries in older adults. Despite differences between included studies, medication review was found to be effective in preventing fall-related injuries and specifically fall-related fractures in community-dwelling older adults. Building on these positive findings, future research should explore the optimal process for conducting medication reviews, the eligibility criteria for-and frequency of - medication reviews, the cooperation between pharmacists and physicians, and compliance to recommendations resulting from medication review. This will contribute to a better fall-related injury prevention for older adults.

\section{CONFLICT OF INTEREST DISCLOSURES}

The authors declare that no conflicts of interest exist.

\section{REFERENCES}

1. He W, Goodkind D, Kowal P. An aging world: 2015. International Population Reports. Washington, DC: US Census; 2016. Available from: https://www.census.gov/content/dam/ Census/library/publications/2016/demo/p95-16-1.pdf

2. Cameron ID, Gillespie LD, Robertson et al. Interventions for preventing falls in older people in care facilities and hospitals. Cochrane Database of Syst Rev. 2018(9):CD005465.

3. Gillespie LD, Robertson MC, Gillespie WJ, et al. Interventions for preventing falls in older people living in the community Cochrane Database Syst Rev. 2012(9).

4. Goldacre MJ, Roberts SE, Yeates D. Mortality after admission to hospital with fractured neck of femur: database study. $B M J$. 2002;325(7369): 868-69.

5. Health Quality Ontario. Prevention of falls and fall-related injuries in community-dwelling seniors: an evidence-based analysis. Ont Health Technol Assess Ser. 2008;8(2):1-78.

6. Masud T, Morris RO. Epidemiology of falls. Age Ageing. 2001;30(Suppl 4):3-7.

7. Rubenstein LZ, Josephson KR. The epidemiology of falls and syncope. Clin Geriatr Med. 2002;18(2):141-58.

8. Gill TM, Murphy TE, Gahbauer EA, et al. Association of injurious falls with disability outcomes and nursing home admissions in community-living older persons. Am J Epidemiol. 2013;178(3):418-25.

9. Todd C, Skelton D. What are the main risk factors for falls amongst older people and what are the most effective interventions to prevent these falls? How should interventions to prevent falls be implemented. Copenhagen, Denmark: World Health Organization, Europe; 2004. Available from: http://www. euro.who.int/_data/assets/pdf_file/0018/74700/E82552.pdf

10. Burns ER, Stevens JA, Lee R. The direct costs of fatal and non-fatal falls among older adults - United States. J Safety Res. 2016;58:99-103.

11. Bergen G, Stevens MR. Falls and fall injuries among adults aged $\geq 65$ years - United States, 2014. Morb and Mortal Wkly Rep. 2016;65(37):993-98.
12. Kaufman DW, Kelly JP, Rosenberg L, et al. Recent patterns of medication use in the ambulatory adult population of the United States: the Slone survey. JAMA. 2002;287(3):337-44.

13. Proulx J, Hunt J. Drug use among seniors on public drug programs in Canada, 2012. Ottawa, ON: CIHI; 2014. Available from: https://secure.cihi.ca/free_products/Drug_Use_in Seniors_on_Public_Drug_Programs_2012_EN_web.pdf

14. Chen Y, Zhu LL, Zhou Q. Effects of drug pharmacokinetic/ pharmacodynamic properties, characteristics of medication use, and relevant pharmacological interventions on fall risk in elderly patients. Ther Clin Risk Manag. 2014;10:437-48.

15. Chung JY. Geriatric clinical pharmacology and clinical trials in the elderly. Transl Clin Pharmacol. 2014;22(2):64-69.

16. Huang AR, Mallet L, Rochefort CM, et al. Medication-related falls in the elderly: causative factors and preventive strategies. Drugs Aging. 2012;29(5):359-76.

17. Rowe JW, Andres R, Tobin JD, et al. The effect of age on creatinine clearance in men: a cross-sectional and longitudinal study. J Gerontol. 1976;31(2):155-63.

18. Tan JL, Eastment JG, Poudel A, et al. Age-related changes in hepatic function: an update on implications for drug therapy. Drugs Aging. 2015;32(12):999-1008.

19. Alldred DP, Raynor DK, Hughes C, et al. Interventions to optimise prescribing for older people in care homes. Cochrane Database Syst Rev. 2013(2):CD009095.

20. Jansen PA, Brouwers JR. Clinical pharmacology in old persons. Scientifica. 2012:1-17.

21. Panel on Prevention of Falls in Older Persons, American Geriatrics Society and British Geriatrics Society. Summary of the updated American Getriatrics Society/ British Geriatrics Society clinical practice guideline for prevention of falls in older persons. J Am Geriatr Soc. 2011;59(1):148-57.

22. Pharmaceutical Care Network Europe. Position paper on the PCNE definition of medication review. Zuidlaren, The Netherlands: PCNE; 2016. Available from: https://www.pcne.org/ upload/files/149_Position_Paper_on_PCNE_Medication_ Review final.pdf

23. Bulajeva A, Labberton L, Leikola S, et al. Medication review practices in European countries. Res Social Adm Pharm. 2014;10(5):731-40.

24. Graabæk T, Kjeldsen LJ. Medication reviews by clinical pharmacists at hospitals lead to improved patient outcomes: a systematic review. Basic Clin Pharmacol Toxicol. 2013;112(6):359-73.

25. Hatah $\mathrm{E}$, Braund $\mathrm{R}$, Tordoff $\mathrm{J}$, et al. A systematic review and meta-analysis of pharmacist-led fee-for-services medication review. Br J Clin Pharmacol. 2014;77(1):102-15.

26. Viswanathan M, Kahwati LC, Golin CE, et al. Medication therapy management interventions in outpatient settings: a systematic review and meta-analysis. JAMA Intern Med. 2015; 175(1):76-87.

27. Wallerstedt SM, Kindblom JM, Nylén K, et al. Medication reviews for nursing home residents to reduce mortality and hospitalization: systematic review and meta-analysis. Br J Clin Pharmacol. 2014;78(3);488-97.

28. Zemansky AG, Alldred DP, Petty DR, et al. Clinical medication review by a pharmacist of elderly people living in care homesrandomised controlled trial. Age Ageing. 2006;35(6):586-91.

29. Christensen M, Lundh A. Medication review in hospitalised patients to reduce morbidity and mortality. Cochrane Database Syst Rev. 2016(2). 
30. Holland R, Desborough J, Goodyer L, et al. Does pharmacistled medication review help to reduce hospital admissions and deaths in older people? A systematic review and meta-analysis. Br J Clin Pharmacol. 2008;65(3):303-16.

31. Huiskes VJ, Burger DM, van den Ende CH, et al. Effectiveness of medication review: a systematic review and meta-analysis of randomized controlled trials. BMC Fam Pract. 2017;18(1):5.

32. Liberati A, Altman DG, Tetzlaff J, et al. The PRISMA statement for reporting systematic reviews and meta-analyses of studies that evaluate health care interventions: explanation and elaboration. PLoS Med. 2009;6(10):e1-34.

33. Jensen J, Lundin-Olsson L, Nyberg L, et al. Fall and injury prevention in older people living in residential care facilities: a cluster randomized trial. Ann Intern Med. 2002;136(10):733-41.

34. Pit SW, Byles JE, Henry DA, et al. A Quality Use of Medicines program for general practitioners and older people: a cluster randomised controlled trial. Med J Aust. 2007;187(1):23-30.

35. Salminen M, Vahlberg T, Kivelä SL. The long-term effect of a multifactorial fall prevention programme on the incidence of falls requiring medical treatment. Public Health. 2009;123(12):809-13.

36. Sjöberg C, Wallerstedt SM. Effects of medication reviews performed by a physician on treatment with fracture-preventing and fall-risk-increasing drugs in older adults with hip fracture - a randomized controlled study. J Am Geriatr Soc. 2013; 61(9):1464-72.

37. Higgins JP, Altman DG, Gøtzsche PC, et al. The Cochrane Collaboration's tool for assessing risk of bias in randomised trials. BMJ. 2011:343.

38. Cochrane Effective Practice and Organisation of Care Group. Suggested risk of bias criteria for EPOC reviews. London, UK: EPOC; 2017. Available from: https://epoc.cochrane.org/ sites/epoc.cochrane.org/files/public/uploads/Resources-for -authors2017/suggested_risk_of_bias_criteria_for_epoc_ reviews.pdf

39. Bangdiwala SI, Bhargava A, O'Connor DP, et al. Statistical methodologies to pool across multiple intervention studies. Transl Behav Med. 2016;6(2):228-35.

40. Conroy S, Kendrick D, Harwood R, et al. A multicentre randomised controlled trial of day hospital-based falls prevention programme for a screened population of community-dwelling older people at high risk of falls. Age Ageing. 2010;39(6):704-10.

41. Davison J, Bond J, Dawson P, et al. Patients with recurrent falls attending Accident \& Emergency benefit from multifactorial intervention - a randomised controlled trial. Age Ageing. 2005;34(2):162-68.

42. Healey F, Monro A, Cockram A, et al. Using targeted risk factor reduction to prevent falls in older in-patients: a randomised controlled trial. Age Ageing. 2004;33(4):390-95.

43. Spice CL, Morotti W, George S, et al. The Winchester falls project: a randomised controlled trial of secondary prevention of falls in older people. Age Ageing. 2009;38(1):33-40.
44. Jensen J, Nyberg L, Gustafson Y, et al. Fall and injury prevention in residential care - effects in residents with higher and lower levels of cognition. J Am Geriatr Soc. 2003;51(5):627-35.

45. Palvanen M, Kannus P, Piirtola M, et al. Effectiveness of the Chaos Falls Clinic in preventing falls and injuries of homedwelling older adults: a randomised controlled trial. Injury. 2014;45(1):265-71.

46. Mikolaizak AS, Lord SR, Tiedemann A, et al. A multidisciplinary intervention to prevent subsequent falls and health service use following fall-related paramedic care: a randomised controlled trial. Age Ageing. 2017;46(2):200-07.

47. Blalock SJ, Casteel C, Roth MT, et al. Impact of enhanced pharmacologic care on the prevention of falls: a randomized controlled trial. Am J Geriatr Pharmacother. 2010;8(5):428-40.

48. Boyé ND, Van der Velde N, De Vries OJ, et al. Effectiveness of medication withdrawal in older fallers: results from the Improving Medication Prescribing to reduce Risk Of FALLs (IMPROveFALL) trial. Age Ageing. 2017;46(1):142-46.

49. Matchar DB, Duncan PW, Lien CT, et al. Randomized controlled trial of screening, risk modification, and physical therapy to prevent falls among the elderly recently discharged from the emergency department to the community: the steps to avoid falls in the elderly study. Arch Phys Med Rehabil. 2017;98(6):1086-96.

50. Registered Nurses' Association of Ontario. Preventing falls and reducing injury from falls, $4^{\text {th }}$ ed. Clinical best practice guideline. Toronto, ON: RNAO; 2017. Available from: https://rnao. ca/sites/rnao-ca/files/bpg/FALL_PREVENTION_WEB_120717.pdf

51. Gallagher PF, O'connor MN, O'mahony D. Prevention of potentially inappropriate prescribing for elderly patients: a randomized controlled trial using STOPP/START criteria. Clin Pharmacol Ther. 2011;89(6):845-54.

52. American Geriatrics Society 2015 Beers Criteria Update Expert Panel. American Geriatrics Society 2015 updated Beers Criteria for potentially inappropriate medication use in older adults. $J$ Am Geriatr Soc. 2015;63(11):2227-46.

53. Hanlon JT, Schmader KE, Samsa GP, et al. A method for assessing drug therapy appropriateness. J Clin Epidemiol. 1992;45(10):1045-51.

54. Hilmer SN, Mager DE, Simonsick EM, et al. Drug burden index score and functional decline in older people. Am J Med. 2009;122(12):1142-49.

55. Blenkinsopp A, Bond C, Raynor DK. Medication reviews. Br J Clin Pharmacol. 2012;74(4):573-80.

Correspondence to: $Y u$ Ming, MD, PhD, Graduate program, Health and Rehabilitation Sciences, School of Health Studies, Western University, 1151 Richmond Street, London, ON N6A 3K7

E-mail: yming5@uwo.ca 


\section{APPENDIX A. PRISMA 2009 CHECKLIST}

\begin{tabular}{|c|c|c|c|}
\hline Section/Topic & & Checklist Item & $\begin{array}{l}\text { Reported } \\
\text { on Page \# }\end{array}$ \\
\hline \multicolumn{4}{|c|}{ Title } \\
\hline Title & 1 & Identify the report as a systematic review, meta-analysis, or both. & 1 \\
\hline \multicolumn{4}{|c|}{ Abstract } \\
\hline $\begin{array}{l}\text { Structured } \\
\text { summary }\end{array}$ & 2 & $\begin{array}{l}\text { Provide a structured summary including, as applicable: background; objectives; data sources; study } \\
\text { eligibility criteria, participants, and interventions; study appraisal and synthesis methods; results; } \\
\text { limitations; conclusions and implications of key findings; systematic review registration number. }\end{array}$ & 2 \\
\hline \multicolumn{4}{|c|}{ Introduction } \\
\hline Rationale & 3 & Describe the rationale for the review in the context of what is already known. & $3-4$ \\
\hline Objectives & 4 & $\begin{array}{l}\text { Provide an explicit statement of questions being addressed with reference to participants, } \\
\text { interventions, comparisons, outcomes, and study design (PICOS). }\end{array}$ & 4 \\
\hline \multicolumn{4}{|c|}{ Methods } \\
\hline $\begin{array}{l}\text { Protocol and } \\
\text { registration }\end{array}$ & 5 & $\begin{array}{l}\text { Indicate if a review protocol exists, if and where it can be accessed (e.g., Web address), and, if } \\
\text { available, provide registration information including registration number. }\end{array}$ & 4 \\
\hline $\begin{array}{l}\text { Eligibility } \\
\text { criteria }\end{array}$ & 6 & $\begin{array}{l}\text { Specify study characteristics (e.g., PICOS, length of follow-up) and report characteristics (e.g., years } \\
\text { considered, language, publication status) used as criteria for eligibility, giving rationale. }\end{array}$ & $4-5$ \\
\hline $\begin{array}{l}\text { Information } \\
\text { sources }\end{array}$ & 7 & $\begin{array}{l}\text { Describe all information sources (e.g., databases with dates of coverage, contact with study authors } \\
\text { to identify additional studies) in the search and date last searched. }\end{array}$ & 4 \\
\hline Search & 8 & $\begin{array}{l}\text { Present full electronic search strategy for at least one database, including any limits used, such that } \\
\text { it could be repeated. }\end{array}$ & 4, App. B \\
\hline Study selection & 9 & $\begin{array}{l}\text { State the process for selecting studies (i.e., screening, eligibility, included in systematic review, and, } \\
\text { if applicable, included in the meta-analysis). }\end{array}$ & Fig. 1 \\
\hline $\begin{array}{l}\text { Data collection } \\
\text { process }\end{array}$ & 10 & $\begin{array}{l}\text { Describe method of data extraction from reports (e.g., piloted forms, independently, in duplicate) } \\
\text { and any processes for obtaining and confirming data from investigators. }\end{array}$ & 5 \\
\hline Data items & 11 & $\begin{array}{l}\text { List and define all variables for which data were sought (e.g., PICOS, funding sources) and any } \\
\text { assumptions and simplifications made. }\end{array}$ & 5 \\
\hline $\begin{array}{l}\text { Risk of bias } \\
\text { in individual } \\
\text { studies }\end{array}$ & 12 & $\begin{array}{l}\text { Describe methods used for assessing risk of bias of individual studies (including specification of } \\
\text { whether this was done at the study or outcome level), and how this information is to be used in any } \\
\text { data synthesis. }\end{array}$ & 5 \\
\hline $\begin{array}{l}\text { Summary } \\
\text { measures }\end{array}$ & 13 & State the principal summary measures (e.g., risk ratio, difference in means). & 5 \\
\hline $\begin{array}{l}\text { Synthesis of } \\
\text { results }\end{array}$ & 14 & $\begin{array}{l}\text { Describe the methods of handling data and combining results of studies, if done, including measures } \\
\text { of consistency }\left(\text { e.g., } \mathrm{I}^{2}\right) \text { for each meta-analysis. }\end{array}$ & 5 \\
\hline $\begin{array}{l}\text { Risk of bias } \\
\text { across studies }\end{array}$ & 15 & $\begin{array}{l}\text { Specify any assessment of risk of bias that may affect the cumulative evidence (e.g., publication bias, } \\
\text { selective reporting within studies). }\end{array}$ & 5 \\
\hline $\begin{array}{l}\text { Additional } \\
\text { analyses }\end{array}$ & 16 & $\begin{array}{l}\text { Describe methods of additional analyses (e.g., sensitivity or subgroup analyses, meta-regression), if } \\
\text { done, indicating which were pre-specified. }\end{array}$ & 6 \\
\hline \multicolumn{4}{|c|}{ Results } \\
\hline Study selection & 17 & $\begin{array}{l}\text { Give numbers of studies screened, assessed for eligibility, and included in the review, with reasons } \\
\text { for exclusions at each stage, ideally with a flow diagram. }\end{array}$ & $\begin{array}{l}\text { Fig. } 1 \text { and } \\
\text { page } 6\end{array}$ \\
\hline $\begin{array}{l}\text { Study } \\
\text { characteristics }\end{array}$ & 18 & $\begin{array}{l}\text { For each study, present characteristics for which data were extracted (e.g., study size, PICOS, } \\
\text { follow-up period) and provide the citations. }\end{array}$ & Tables $1 \& 2$ \\
\hline
\end{tabular}


APPENDIX A. PRISMA 2009 CHECKLIST (continued)

\begin{tabular}{|c|c|c|c|}
\hline Section/Topic & & Checklist Item & $\begin{array}{l}\text { Reported } \\
\text { on Page \# }\end{array}$ \\
\hline \multicolumn{4}{|c|}{ Results continued } \\
\hline $\begin{array}{l}\text { Risk of bias } \\
\text { within studies }\end{array}$ & 19 & $\begin{array}{l}\text { Present data on risk of bias of each study and, if available, any outcome level assessment (see } \\
\text { item 12). }\end{array}$ & Figs. 2, 3 \\
\hline $\begin{array}{l}\text { Results of } \\
\text { individual } \\
\text { studies }\end{array}$ & 20 & $\begin{array}{l}\text { For all outcomes considered (benefits or harms), present, for each study: (a) simple summary data } \\
\text { for each intervention group (b) effect estimates and confidence intervals, ideally with a forest plot. }\end{array}$ & $\begin{array}{l}\text { Table } 2, \\
\text { Figs. } 4,5,6\end{array}$ \\
\hline $\begin{array}{l}\text { Synthesis of } \\
\text { results }\end{array}$ & 21 & $\begin{array}{l}\text { Present results of each meta-analysis done, including confidence intervals and measures of } \\
\text { consistency. }\end{array}$ & Figs. $4,5,6$ \\
\hline $\begin{array}{l}\text { Risk of bias } \\
\text { across studies }\end{array}$ & 22 & Present results of any assessment of risk of bias across studies (see Item 15). & N/A \\
\hline $\begin{array}{l}\text { Additional } \\
\text { analysis }\end{array}$ & 23 & $\begin{array}{l}\text { Give results of additional analyses, if done (e.g., sensitivity or subgroup analyses, meta-regression } \\
\text { [see Item 16]). }\end{array}$ & Figs. $4,7,8$ \\
\hline \multicolumn{4}{|c|}{ Discussion } \\
\hline $\begin{array}{l}\text { Summary of } \\
\text { evidence }\end{array}$ & 24 & $\begin{array}{l}\text { Summarize the main findings including the strength of evidence for each main outcome; consider } \\
\text { their relevance to key groups (e.g., healthcare providers, users, and policy makers). }\end{array}$ & 10 \\
\hline Limitations & 25 & $\begin{array}{l}\text { Discuss limitations at study and outcome level (e.g., risk of bias), and at review-level (e.g., } \\
\text { incomplete retrieval of identified research, reporting bias). }\end{array}$ & $11-12$ \\
\hline Conclusions & 26 & $\begin{array}{l}\text { Provide a general interpretation of the results in the context of other evidence, and implications for } \\
\text { future research. }\end{array}$ & 12 \\
\hline \multicolumn{4}{|c|}{ Funding } \\
\hline Funding & 27 & $\begin{array}{l}\text { Describe sources of funding for the systematic review and other support (e.g., supply of data); role of } \\
\text { funders for the systematic review. }\end{array}$ & 1 \\
\hline
\end{tabular}

\section{APPENDIX B. SEARCH STRATEGY FOR PUBMED: FULL SEARCH TERMS}

$(((()((()((($ “seniors”[Title/Abstract]) OR “senior citizen”[Title/Abstract]) OR “senior citizens”[Title/Abstract]) OR “older people"[Title/Abstract]) OR “old people"[Title/Abstract]) OR “old person"[Title/Abstract]) OR “old persons"[Title/Abstract]) OR “older adults"[Title/Abstract]) OR "elderly"[Title/Abstract]) OR "geriatric"[Title/Abstract]) OR "aged”[Title/Abstract])) AND ((()(“accidental falls”) OR ((“fall” OR “falls”))) OR falling) OR “accidental fall”))) AND $((()(()(()((()(()((()(()(()((()$ “Wo unds and Injuries”[Majr]) AND “Abdominal Injuries”[Mesh]) AND “Amputation, Traumatic”[Mesh]) OR “Arm Injuries”[Mesh]) OR “Back Injuries”[Mesh]) OR “Spinal Injuries”[Mesh]) OR “Fractures, Bone”[Mesh]) OR "Fractures, Cartilage”[Mesh]) OR "Hand Injuries"[Mesh]) AND “Hip Injuries"[Mesh]) OR “Joint Dislocations"[Mesh]) OR "Lacerations”[Mesh]) OR "Leg Injuries”[Mesh]) OR “Multiple Trauma”[Mesh]) OR "Nasal Septal Perforation”[Mesh]) OR "Neck Injuries”[Mesh]) OR "Rupture"[Mesh]) OR "Shoulder Injuries"[Mesh]) OR "Soft Tissue Injuries”[Mesh]) OR "Spinal Cord Injuries”[Mesh]) OR "Sprains and Strains”[Mesh]) OR “Tendon Injuries”[Mesh]) OR “Thoracic Injuries”[Mesh]) OR “Tooth Injuries”[Mesh]) OR "Trauma, Nervous System"[Mesh]) OR "Vascular System Injuries”[Mesh]) OR "Wounds, Nonpenetrating”[Mesh]) OR "Wounds, Penetrating"[Mesh])) OR ((“fall-related injury" OR "fall-related injuries" OR "fall related injury" OR "fall related injuries"))) OR (“fall related hospitalization” OR "fall-related hospitalization”)))) AND $((()((()(()(()(()(()(()(()((()($ cpharmaceutical services") OR ("Pharmaceutical Services”[Mesh] OR "Pharmaceutical Services, Online”[Mesh] OR "Community Pharmacy Services"[Mesh] OR "Pharmacy Service, Hospital"[Mesh])) OR "medication therapy management") OR (( "Medication Therapy Management/classification"[Majr] OR "Medication Therapy Management/legislation and jurisprudence"[Majr] OR "Medication Therapy Management/organization and administration"[Majr] OR "Medication Therapy Management/standards"[Majr] OR "Medication Therapy Management/statistics and numerical data"[Majr] OR "Medication Therapy Management/trends"[Majr] OR “Medication Therapy Management/utilization”[Majr]))) OR “drug utilization review") OR “Drug Utilization Review”[Mesh]) OR $(((()(()((()(((c$ "pharmacist review”) OR “pharmacist reviews”) OR “pharmacist intervention”) OR "pharmacist interventions") OR "pharmacist program") OR "pharmacist programs") OR "pharmacist assessment”) OR "pharmacist assessments") 
OR "pharmacist consult") OR "pharmacist consults") OR "pharmacist evaluation") OR "pharmacist evaluations") OR "pharmacist counselling”) OR "pharmacist care")) OR (pharmacist consultation') OR 'pharmacist consultations'))) OR (()((()((()(()((“"pharmacologist review”) OR “pharmacologist reviews”) OR "pharmacologist intervention”) OR “pharmacologist interventions”) OR "pharmacologist program”) OR “pharmacologist programs”) OR "pharmacologist assessment”) OR "pharmacologist assessments") OR "pharmacologist consult") OR "pharmacologist consults") OR "pharmacologist evaluation") OR "pharmacologist evaluations") OR "pharmacologist counselling") OR "pharmacologist care")) OR "pharmacologist consultation”) OR “pharmacologist consultations”))) OR ((()((((()(((()((“drug review”) OR “drug reviews”) OR “drug intervention”) OR “drug interventions”) OR “drug program”) OR “drug programs”) OR “drug assessment”) OR "drug assessments") OR "drug consult") OR “drug consults") OR "drug evaluation") OR "drug evaluations") OR "drug counselling”) OR "drug care”)) OR “drug consultation”) OR “drug consultations”))) OR (((c((()(((c((c(((“drugs review”) OR “drugs reviews") OR “drugs intervention") OR “drugs interventions") OR “drugs program”) OR "drugs programs”) OR “drugs assessment”) OR "drugs assessments”) OR “drugs consult") OR “drugs consults") OR “drugs evaluation”) OR “drugs evaluations") OR “drugs counselling”) OR "drugs care”)) OR “drugs consultations”) OR “drugs consultation”)) ) OR ((((()((((()((()(“medication review”) OR “medication reviews”) OR "medication intervention") OR "medication interventions") OR "medication program") OR "medication programs") OR "medication assessment") OR "medication assessments") OR "medication consult") OR "medication consults") OR "medication evaluation") OR "medication evaluations") OR "medication counselling") OR "medication care")) OR "medication consultation”) OR “medication consultations”))) OR ((()((()((()(((()(medications review”) OR “medications reviews”) OR “medications intervention") OR "medications interventions") OR "medications program") OR "medications programs") OR "medications assessment") OR "medications assessments") OR "medications consult") OR "medications consults") OR "medications evaluation") OR "medications evaluations") OR "medications counselling") OR "medications care")) OR "medications consultation") OR “medications consultations”)) ) OR ((()((()(((()((((“medicine review”) OR “medicine reviews”) OR “medicine intervention”) OR “medicine interventions") OR "medicine program”) OR “medicine programs") OR “medicine assessment”) OR "medicine assessments") OR “medicine consult") OR "medicine consults") OR “medicine evaluation") OR "medicine evaluations") OR "medicine counselling") OR "medicine care")) OR "medicine consultation") OR "medicine consultations"))) OR (()((()((()((()((“"medicines review”) OR “medicines reviews”) OR “medicines intervention”) OR “medicines interventions") OR “medicines program") OR "medicines programs") OR "medicines assessment”) OR "medicines assessments") OR "medicines consult") OR "medicines consults") OR "medicines evaluation") OR "medicines evaluations") OR "medicines counselling”) OR “medicines care")) OR “medicines consultation”) OR “medicines consultations”)))) OR ((((()((((()((((()(pharmaceuticals review") OR "pharmaceuticals reviews") OR "pharmaceuticals intervention") OR "pharmaceuticals interventions") OR "pharmaceuticals programs") OR "pharmaceuticals program") OR "pharmaceuticals assessment”) OR "pharmaceuticals assessments") OR "pharmaceuticals consult") OR "pharmaceuticals consults") OR "pharmaceuticals evaluation") OR "pharmaceuticals evaluations") OR "pharmaceuticals counselling") OR "pharmaceuticals care")) OR "pharmaceuticals consultation") OR "pharmaceuticals consultations")))) OR $(((()((()(()((()($ "pharmaceutic review”) OR "pharmaceutic reviews") OR "pharmaceutic intervention") OR "pharmaceutic interventions") OR "pharmaceutic program") OR "pharmaceutic programs") OR "pharmaceutic assessment") OR "pharmaceutic assessments") OR "pharmaceutic consult") OR "pharmaceutic consults") OR "pharmaceutic evaluation") OR "pharmaceutic evaluations") OR "pharmaceutic counselling") OR "pharmaceutic care")) OR "pharmaceutic consultation") OR "pharmaceutic consultations"))) OR (((C((()((()((()(“"pharmaceutics review”) OR "pharmaceutics reviews") OR "pharmaceutics intervention") OR "pharmaceutics interventions") OR "pharmaceutics program") OR "pharmaceutics programs") OR "pharmaceutics assessment") OR "pharmaceutics assessments") OR "pharmaceutics consult") OR "pharmaceutics consults") OR "pharmaceutics evaluation") OR "pharmaceutics evaluations") OR "pharmaceutics counselling") OR "pharmaceutics care")) OR "pharmaceutics consultation”) OR "pharmaceutics consultations”))) OR (((()((()((()((((c"pharmacology review") OR "pharmacology reviews") OR "pharmacology intervention") OR "pharmacology interventions") OR "pharmacology program") OR "pharmacology programs") OR "pharmacology assessment") OR "pharmacology assessments") OR "pharmacology consult") OR "pharmacology consults") OR "pharmacology evaluation") OR "pharmacology evaluations") OR "pharmacology counselling") OR "pharmacology care")) OR "pharmacology consultation") OR "pharmacology consultations"))) OR $((()((()(()(()($ ("pharmacotherapeutic review”) OR “pharmacotherapeutic reviews”) OR "pharmacotherapeutic intervention”) OR "pharmacotherapeutic interventions") OR "pharmacotherapeutic program") OR "pharmacotherapeutic programs") OR "pharmacotherapeutic assessment") OR "pharmacotherapeutic assessments") OR "pharmacotherapeutic consult") OR "pharmacotherapeutic consults") OR "pharmacotherapeutic evaluation") OR "pharmacotherapeutic evaluations") OR "pharmacotherapeutic counselling") OR "pharmacotherapeutic care")) OR "pharmacotherapeutic consultation") OR "pharmacotherapeutic consultations")) OR ((()((()(()((()("pharmacotherapeutics review”) OR “pharmacotherapeutics reviews") OR “pharmacotherapeutics intervention") OR "pharmacotherapeutics interventions") OR "pharmacotherapeutics program") OR "pharmacotherapeutics programs") OR "pharmacotherapeutics assessment") OR "pharmacotherapeutics assessments") OR "pharmacotherapeutics consult") OR "pharmacotherapeutics consults") OR "pharmacotherapeutics evaluation") OR "pharmacotherapeutics evaluations") OR "pharmacotherapeutics counselling") OR "pharmacotherapeutics care")) OR "pharmacotherapeutics consultation") OR "pharmacotherapeutics consultations")) OR ((()((()((c((()("pharmacotherapy review”) OR "pharmacotherapy reviews”) OR 
"pharmacotherapy intervention") OR "pharmacotherapy interventions") OR "pharmacotherapy programs") OR "pharmacotherapy program") OR "pharmacotherapy assessment") OR "pharmacotherapy assessments") OR "pharmacotherapy consult") OR "pharmacotherapy consults") OR "pharmacotherapy evaluation") OR "pharmacotherapy evaluations") OR "pharmacotherapy counselling”) OR "pharmacotherapy care")) OR "pharmacotherapy consultation”) OR "pharmacotherapy consultations")) OR ((()((()((()(((c"pharmacy review”) OR “pharmacy reviews”) OR “pharmacy intervention”) OR "pharmacy interventions”) OR "pharmacy program") OR "pharmacy programs") OR "pharmacy assessment") OR "pharmacy assessments") OR "pharmacy consult") OR "pharmacy consults") OR "pharmacy evaluation") OR "pharmacy evaluations") OR "pharmacy counselling") OR "pharmacy care”)) OR "pharmacy consultation”) OR "pharmacy consultations”)) OR (((()((()((()(((“pharmacies review”) OR "pharmacies reviews") OR "pharmacies intervention") OR "pharmacies interventions") OR "pharmacies program") OR "pharmacies programs") OR "pharmacies assessment") OR "pharmacies assessments") OR "pharmacies consult") OR "pharmacies consults") OR "pharmacies evaluation") OR "pharmacies evaluations") OR "pharmacies counselling") OR "pharmacies care")) OR "pharmacies consultation”) OR "pharmacies consultations”)) OR ((()((()((()(((c"polypharmacy review”) OR “polypharmacy reviews") OR "polypharmacy intervention”) OR "polypharmacy interventions”) OR “polypharmacy program") OR "polypharmacy programs") OR "polypharmacy assessment") OR "polypharmacy assessments") OR "polypharmacy consult") OR "polypharmacy consults") OR "polypharmacy evaluation") OR "polypharmacy evaluations") OR "polypharmacy counselling") OR "polypharmacy care”)) OR “polypharmacy consultation”) OR "polypharmacy consultations")) OR ((()((()((()((((c"prescription review”) OR "prescription reviews") OR "prescription intervention”) OR "prescription interventions") OR "prescription program") OR "prescription programs") OR "prescription assessment") OR "prescription assessments") OR "prescription consult") OR "prescription consults") OR "prescription evaluation") OR "prescription evaluations") OR "prescription counselling") OR "prescription care")) OR “prescription consultation”) OR “prescription consultations”)) OR (((()((()((()(((“prescriptions review") OR “prescriptions reviews”) OR "prescriptions intervention") OR “prescriptions interventions”) OR "prescriptions program") OR “prescriptions programs") OR "prescriptions assessment”) OR "prescriptions assessments") OR "prescriptions consult") OR "prescriptions consults") OR "prescriptions evaluation") OR "prescriptions evaluations") OR "prescriptions counselling") OR “prescriptions care”)) OR "prescriptions consultation”) OR “prescriptions consultations”)) OR ((()((()((()((((“"prescribing review") OR "prescribing reviews") OR "prescribing intervention") OR "prescribing interventions") OR "prescribing program") OR "prescribing programs") OR "prescribing assessment") OR "prescribing assessments") OR "prescribing consult") OR "prescribing consults") OR "prescribing evaluation") OR "prescribing evaluations") OR "prescribing counselling") OR "prescribing care”)) OR "prescribing consultation”) OR “prescribing consultations”)) OR ((((()((()((()((“pharmacist’s review”) OR "pharmacist's reviews") OR "pharmacist's intervention") OR "pharmacist's interventions") OR "pharmacist's program”) OR "pharmacist's program") OR "pharmacist's assessment”) OR "pharmacist's assessments") OR "pharmacist's consult") OR "pharmacist's consults") OR "pharmacist's evaluation") OR "pharmacist's evaluations") OR "pharmacist's counselling") OR "pharmacist’s care")) OR "pharmacist's consultation”) OR "pharmacist’s consultations")) OR ((()((()((()(((("pharmacists review") OR "pharmacists reviews") OR "pharmacists intervention") OR "pharmacists interventions") OR "pharmacists program") OR "pharmacists programs") OR "pharmacists assessment") OR "pharmacists assessments") OR "pharmacists consult") OR "pharmacists consults") OR "pharmacists evaluation") OR "pharmacists evaluations") OR "pharmacists counselling”) OR “pharmacists care”)) OR “pharmacists consultation”) OR “pharmacists consultations”)) OR ((()((()((()((((“pharmacists” review”) OR “pharmacists' reviews”) OR "pharmacists' intervention”) OR "pharmacists' interventions”) OR “pharmacists' program”) OR "pharmacists' programs") OR "pharmacists' assessment") OR "pharmacists' assessments") OR "pharmacists' consult") OR "pharmacists" consults”) OR "pharmacists' evaluation”) OR "pharmacists' evaluations") OR "pharmacists' counselling”) OR "pharmacists" care”)) OR “pharmacists' consultation”) OR “pharmacists’ consultations”)) OR (()((()((()((()("pharmacologist’s review”) OR "pharmacologist's reviews") OR "pharmacologist's intervention”) OR "pharmacologist's interventions") OR "pharmacologist's programs") OR "pharmacologist's program") OR "pharmacologist's assessment") OR "pharmacologist's assessments") OR "pharmacologist's consult") OR "pharmacologist's consults") OR "pharmacologist's evaluation") OR "pharmacologist's evaluations") OR "pharmacologist's counselling") OR “pharmacologist's care")) OR "pharmacologist's consultation”) OR “pharmacologist’s consultations”)) OR ((()((()((()(((c"pharmacologists review”) OR “pharmacologists reviews”) OR "pharmacologists intervention") OR "pharmacologists interventions") OR "pharmacologists programs") OR "pharmacologists program") OR "pharmacologists assessment") OR "pharmacologists assessments") OR "pharmacologists consult") OR "pharmacologists consults") OR "pharmacologists evaluation") OR "pharmacologists evaluations") OR "pharmacologists counselling") OR "pharmacologists care")) OR "pharmacologists consultation") OR "pharmacologists consultations")) OR ((()(()((()(()((“pharmacologists’ review”) OR “pharmacologists’ reviews”) OR “pharmacologists' intervention”) OR “pharmacologists' interventions") OR "pharmacologists' programs") OR "pharmacologists' program") OR "pharmacologists" assessment”) OR “pharmacologists' assessments") OR "pharmacologists' consult”) OR “pharmacologists' consults") OR "pharmacologists' evaluation") OR "pharmacologists' evaluations") OR “pharmacologists' counselling") OR “pharmacologists' care")) OR “pharmacologists' consultation”) OR “pharmacologists' consultations")) 